\title{
Методические аспекты форензик-контроля как инструмента выявления и предотвращения мошеннических действий в деятельности экономических субъектов
}

\author{
Ж. А. Кеворкова ${ }^{1 凶}$ \\ 1 Финансовый университет при Правительстве Российской Федерации, \\ Ленинградский пр., 49, 125993, ГСП-3, Москва, Российская Федерация
}

Для цитирования: Кеворкова Ж. А. Методические аспекты форензик-контроля как инструмента выявления и предотвращения мошеннических действий в деятельности экономических субъектов // Вестник Воронежского государственного университета. Серия: Экономика и управление. 2020. № 4. С. 43-53. DOI: $10.17308 /$ econ.2020.4/3192

\begin{abstract}
Предмет. В статье раскрываются методические аспекты форензика как инструмента выявления и предотвращения мошеннических действий в деятельности экономических субъектов. Обоснована целевая направленность и результативность использования форензик как метода, применяемого при проверках. При этом показано, что применение форензик как инструмента выявления мошеннических действий в экономических субъектах имеет определенные особенности, сопряженные с отраслевой спецификой исследуемого субъекта.

Цели/задачи. Расширено исследование спектра услуг, предоставляемых организациями, работающими в данной области. Доказано, что при решении вопросов по данной проблеме имеется большое количество дискуссионных положений, требующих научных исследований, которые раскрываются в данной статье, определены ключевые факторы, разбор которых необходим для выявления фальсифицированной финансовой отчетности.

Методология. Исследование проводилось посредством применения как общенаучных методов познания, включающих анализ, классификацию, систематизацию, обобщение, сравнение, так и частных методов. Определено, что применение методики форензик-контроля как инструмента выявления мошеннических действий в экономических субъектах сопряжено с определенными трудностями, при его применении необходимо учитывать экономические и юридические положения.

Результаты. Анализ деятельности экономического субъекта, его информационной базы направлен на выявление индикаторов мошенничества, свидетельствующих о возможном наличии мошеннических действий в отношении исследуемого экономического субъекта.

Выводы. Исследование методологических разработок и полученных результатов применения форензик позволило выявить проблемы, решение которых направлено на выработку предложений по его применению как инструмента выявления и предупреждения мошеннических действий в деятельности экономических субъектов.
\end{abstract}

Ключевые слова: форензик, мошеннические действия, задачи форензик, метод форензик, финансовые расследования, внесудебная экономическая экспертиза.

\section{Введение}

Независимо от организационно-правовой формы субъектов, их отраслевой принадлежности и других факторов практически все экономические преступления связаны с деятельностью экономических субъектов. Результаты обзора различных источников информации, в частности Всемирного обзора экономических

(C) Кеворкова Ж. А., 2020

Вестник ВГУ. Серия: Экономика и управление. 2020. № 4. C. $43-53$. преступлений за 2018 год, проведенного компанией $\mathrm{PwC}^{1}$, показывают, что практически каждая третья организация столкнулась с разными видами мошенничества, связанными с фактами коррупции, вывода и хищений активов, искажений бухгалтерской (финансовой) отчетности, фиктивного и преднамеренного банкротства, налоговых преступлений. Наибо-

${ }^{1}$ URL: http: www.pwc.by/ru/publications/otherpublications/economic-crime-survey-2018.html 
лее известной гипотезой, объясняющей причины совершения человеком мошеннических действий, является гипотеза Д. Р. Кресси, построенная в форме равностороннего треугольника, вершинами которого являются «давление», «возможность», «оправдание». Поиск и предупреждение таких нестандартных ситуаций в деятельности организаций требуют применения новых, более эффективных способов и инструментов их выявления, к которым можно отнести форензик, или так называемое финансовое расследование в области экономики.

Современные исследования причин и факторов мошенничества в большинстве своем основываются на работе Э. Х. Сазерленда, который в 1939 г. ввел понятие «преступления белых воротничков», определяемые им как «незаконные действия корпораций и их высших должностных лиц с использованием служебного положения» [11; 12]. В настоящее время сущность и содержание данного понятия расширены, оно включает практически все виды экономических преступлений.

Системные исследования, посвященные проблеме выявления и предотвращения мошеннических действий, представлены в трудах российских и зарубежных ученых: М. А. Городилова и Н. А. Шкляевой [13], Е. Исаевой [14], В. Г. Когденко [16], В. П. Суйца и И. И. Анушевского [17], Дж. Т. Уэллса [18], Д. Т. Вулфа и Д.Р. Хермансона [4], R. D. Hernandez и T. Groot [5], P. Ozili [8], F. Y. Ozkul и A. Pamukcu [9], D. Crumbley и др. [2], G. Manning [7], K. Dreyer [3]. Не умаляя достоинств полученных приведенными выше авторами результатов, следует отметить, что многие из них рассматривают теоретические положения мошеннических действий и исторические подходы к методикам их выявления, классификации, применения форензика и его экономической природы и сущности, правовые основы, информационное обеспечение. Основная часть работ зарубежных ученых раскрывает в большей степени теоретические положения и исторический аспект развития форензика, а соответственно, не учитывают современных тенденций в деятельности экономических субъектов. Поэтому возникает необходимость разработки методических подходов к практике применения форензика как инструмента выявления мошеннических действий в экономических субъектах, имеющих определенные особенности, сопряженные с отраслевой спецификой объекта.

Целью проводимого исследования является разработка методических подходов к форен- зику как методу контроля. Для достижения поставленной цели необходимо выявить преимущества и недостатки данного метода, возможности его применения при проверке российских организаций с учетом знания существующих методов незаконного присвоения, вывода или хищения активов и других видов мошенничества.

\section{Материалы и методы исследования}

Исследование основано на результатах анализа содержания заключения аудиторских организаций, в структуре которых выделен в самостоятельное подразделение департамент (группа) контролеров, оказывающих услуги форензика, а также на материалах и практическом опыте специалистов организаций, предоставляющих услуги форензика.

Данное исследование проводилось посредством применения как общенаучных методов познания, включающих анализ, синтез, классификацию, систематизацию, обобщение, группировку, сравнение, так и частных методов (экспертных оценок, наблюдения, изучения документов, критического анализа, системного и аналитического подходов), целесообразность применения которых подтверждена полученными результатами.

Методологическую и теоретическую основу исследования составили положения, связанные с развитием понятийного аппарата, организационных характеристик, методического инструментария, разработанных и систематизированных отечественными и зарубежными учеными, посвященные различным аспектам мошенничества. При подготовке исследования использованы конкретные предложения ученых и практиков, посвященные вопросам выявления и предупреждения мошеннических действий в деятельности экономических субъектов, международному опыту формирования учетной информации. Концептуальные проблемы, содержащиеся в исследованиях российских и зарубежных ученых по вопросам развития методологии форензика, позволили сформировать методические подходы к применению форензик-контроля как инструмента выявления и предотвращения мошенничества в деятельности экономических субъектов.

\section{Обсуждение результатов}

Исследования Эдвина Х. Сазерленда продолжил Дональд Р. Кресси, выдвинувший гипотезу, названную «треугольником мошенничества» и состоящую в следующем: «Доверенные 
Методические аспекты форензик-контроля как инструмента...

лица становятся "преступниками на доверии" в том случае, если они начинают испытывать финансовые затруднения, о которых не могут говорить публично, возможным выходом считают совершение тайных финансовых махинаций и способны применять к своему поведению в данной ситуации объяснения, позволяющие примирить представления о себе как об обличенных доверием лицах и как о пользователях вверенных средств или имущества» [1].

Следует отметить, что сегодня в литературе существуют дискуссионные моменты относительно наличия связи между стимулами, возможностями и рационализацией. Тем не менее нет согласия среди ученых и практиков относительно порядка или последовательности возникновения мошенничества для каждого компонента «треугольника мошенничества» (давление, возможности, рационализация).

В нескольких исследованиях предпринимались попытки расширить «треугольник мошенничества». Ученые Д. Т. Вулф и Д. Р. Хермансон в 2004 г. добавили к нему четвертое измерение - «способность» («capability») [4]. Впоследствии новое образование было названо «ромбом мошенничества». Согласно результатам исследования сторона «ромба мошенничества»-«способность»- обращена к реальности, т. е. некоторые люди не будут совершать мошенничество, даже если присутствуют все три исходных фактора (давление, возможности, рационализация). Исполнитель должен иметь «способность» совершить мошеннический акт с некоторой уверенностью в том, что он не будет обнаружен [4].

Кроме того, 3. Резайи в своих исследованиях представляет альтернативу мошенническому треугольнику как попытку выявить потенциальные причины мошенничества [10]. Он исследовал факторы, позволяющие увеличить вероятность совершения мошенничества, приравнивая тенденции мошенничества к концепции CRIME, позволяющей определить пять ключевых факторов, исследование которых необходимо для полноценного анализа фальсифицированной финансовой отчетности:

- фальсифицировать документы (Cooking the books);

- методы мошенничества (Recipes);

- мотивы, цели (Incentives);

- мониторинг/контроль или его недостаток (Monitoring lack of it);

- результаты фальсификации (End results).

Основываясь на анализе CRIME, 3. Резайи был сделан вывод, что «мошенничество с фи- нансовой отчетностью представляет собой серьезную угрозу для потери доверия инвесторов к финансовой информации» [10].

Из более поздних исследований необходимо также отметить работу американских ученых Краначера и его коллег, которые сформулировали свой подход для объяснения мотивации для совершения мошенничества, названный МICЕ. Расшифровывается аббревиатура как Money, Ideology, Coercion, and Ego/ Entitlement, что в переводе с английского означает «Деньги, идеология, принуждение, эго/причитающиеся выплаты», являющиеся мотивами совершения мошенничества [6]. В своем анализе они поддерживали структуру «треугольника мошенничества», но использовали соединенный треугольник, подобный «ромбу мошенничества», представленному Д. Т. Вулфом и Д. Р. Хермансоном [4].

Таким образом, проблема мошенничества на сегодняшний день весьма актуальна. Общество нуждается в современных подходах к ее выявлению и устранению, поэтому форензик-контроль становится все более востребованным. В качестве одной из главных задач форензик-контроля выступает выявление не только фактов намеренного искажения финансовой отчетности, но и фактов фальсификации первичной документации и данных регистров бухгалтерского учета. Анализ системы внутреннего контроля и регистров бухгалтерского учета направлен на выявление индикаторов мошенничества, т. е. признаков, свидетельствующих о возможном наличии мошеннических действий в отношении исследуемого экономического субъекта. В случае обнаружения мошеннических действий в заключении по результатам проведения форензик-контроля обязательно должно быть отмечено, что показатели индикаторов мошенничества свидетельствуют о высокой вероятности корпоративного мошенничества и неадекватной реакции руководства на такую информацию.

Соблюдение этических требований и требований ответственности перед обществом становится более уязвимым перед использованием различных мошеннических схем, которые впоследствии могут быть квалифицированы как экономические преступления. При этом в таких действиях замешаны не только сотрудники экономических субъектов, но и партнеры по бизнесу, связанные стороны, инвесторы, кредиторы и другие контрагенты. Для экономических субъектов нарушения внутрикорпоративных и законодательных норм могут 
привести не только к финансовым потерям, но и к необратимым последствиям в виде понижения курса акций, снижения имиджа организации и уровня деловой репутации, инвестиционной привлекательности субъекта, потери рынка сбыта и др.

В настоящее время состав экономических преступлений, как в мировой практике, так и в России, остается традиционным. Самыми распространенными видами мошеннических действий являются незаконное присвоение или вывод активов, недостоверность финансовой отчетности, мошенничество в сфере закупок товаров и услуг, взяточничество и коррупция, киберугрозы, легализация денежных средств.

Форензик как метод контроля в большинстве случаев направлен на разрешение основных видов мошенничества, которые впервые были классифицированы в исследовании Дж. Т. Уэллса [18]:

- мошенничество с финансовой отчетностью;

- незаконное присвоение или вывод активов;

- коррупция.

Результаты обзора зарубежной и российской экономической литературы демонстрируют, что в основном их содержание направлено на выявление мошеннических действий с бухгалтерской (финансовой) отчетностью.

Систематизация и группировка полученных результатов исследования показывает, что мошеннические действия с бухгалтерской (финансовой) отчетностью в большей степени отображают:

- преднамеренные искажения первичных учетных документов и регистров текущего учета, отдельных фактов хозяйственной жизни на предмет завышения или занижения стоимости активов и обязательств;

- неправильную классификацию статей бухгалтерской (финансовой) отчетности, упущения или недостоверное отражение фактов и хозяйственных ситуаций в системе счетов; использование счетов, не утвержденных в учетной политике и другой важной информации, являющихся основой подготовки бухгалтерской (финансовой) отчетности в части завышения или занижения величины выручки, себестоимости, прочих доходов и расходов и других количественных показателей;

- преднамеренное или неправильное применение российских федеральных и международных стандартов учета и финансовой отчетности, принципов, элементов учетной политики, манипулирование методами и способами ведения бухгалтерского учета;
- умышленные (преднамеренные) упущения при раскрытии или представлении финансовой и нефинансовой информации, пренебрежение раскрытием важных пояснений и примечаний к бухгалтерской (финансовой) отчетности или искажение данных в них.

Следовательно, можно утверждать, что мошеннические действия (вуалирование, налоговая оптимизация, фальсификация, налоговые преступления) с финансовой отчетностью - это преднамеренная попытка руководства, топ-менеджмента дезинформировать или ввести в заблуждение внешних пользователей опубликованной финансовой отчетности, в особенности учредителей, инвесторов, кредиторов, связанные стороны путем подготовки и распространения существенно искаженной финансовой отчетности.

Мошеннические действия, связанные со счетами бухгалтерского учета, часто проявляются путем манипулирования с данными, используемыми для формирования финансовой отчетности. Например, это могут быть некорректная (недостоверная) оценка (или переоценка) активов и обязательств, неправильный расчет капитализированных расходов, недостоверное определение величины рисков и их влияния на финансовый результат, неоприходование запасов, неотражение доходов средствами учета, использование доходов на неуставные виды деятельности, получение выгод от завышения личных расходов руководителя, выравнивание доходов и расходов по периодам в целях налогообложения и т. п.

Незаконное присвоение, вывод или хищение активов являются другим направлением мошеннических действий, представляющих собой действия топ-менеджмента, наемного персонала, связанных сторон и других третьих лиц, непосредственно направленных на активы юридического лица. Так, незаконное присвоение, вывод или хищение активов может быть в виде:

- сокрытия или присвоения прибыли (доходов);

- хищения денежных средств и других видов активов, подделки расчетных и финансовых документов;

- прибыли (дохода), полученного при осуществлении незаконной предпринимательской деятельности;

- использования мошеннических схем, связанных с неправомерной выплатой денежных средств, выставления и оплаты счетов-фактур, в том числе с использованием информационных технологий; 
Методические аспекты форензик-контроля как инструмента...

- мошеннических схем с внеоборотными и оборотными активами, ценными бумагами, инвестициями в долговые и долевые инструменты и другими активами и т. п.;

- использования схем мошенничества, основанных на исполнении обязательств перед контрагентами экономических субъектов;

- незаконного сокращения налоговых обязательств;

- использования схем мошенничества, основанных на учете активов по справедливой стоимости и применения профессионального суждения и др.

Не обнаруженные своевременно факты недостачи, вывода, присвоения, хищения активов влекут за собой искажение показателей отдельных статей бухгалтерской (финансовой) отчетности в отношении предпосылки аудита «существование» при ее подготовке и формировании. При применении данной нормы может быть установлено, что актив в действительности отсутствовал на отчетную дату, но был отражен в составе других статей активов в бухгалтерской (финансовой) отчетности. Подтверждением могут быть результаты инвентаризации, проведенной с применением метода анализа ежедневного движения материальных ценностей. Применение методов фактического контроля позволяет обнаружить факты недостач, вывода, присвоения или хищения активов, которые в бухгалтерском учете необходимо переквалифицировать в недостающий актив и отразить как убыток (если виновное лицо не установлено), или включить в состав дебиторской задолженности (если виновное лицо определено). Выявленные негативные факты оказывают существенное влияние на бухгалтерскую (финансовую) отчетность при условии существенной стоимости недостающих активов. При этом экспертом в области форензика рассматриваются не только механизмы осуществления экономических преступлений, но и методы их сокрытия. Например, был осуществлен материальный или интеллектуальный подлог, проведена подмена оригинальных документов фальсифицированными, уменьшена стоимость выведенных активов и др. Следовательно, чем больше стоимость фактов выявленных недостач, вывода, присвоения, хищений активов, тем больше величина материальных последствий (ущерба), наносимых организации, государству и другим контрагентам.

Под определение коррупции как третьей составляющей мошенничества подпадают коммерческий подкуп, принятие неразрешенных подарков, взяточничество, экономическое вымогательство.
Так, коммерческий подкуп в соответствии с нормами ст. 204 Уголовного кодекса Российской Федерации представляет собой взаимоотношения между физическими лицами (представляющими связанные стороны или третьи лица), приводящие к искажению показателей бухгалтерской (финансовой) отчетности, но опосредованно. В результате коммерческого подкупа могут быть предприняты и другие противоправные действия виновного лица, которые приведут к искажению показателей бухгалтерской (финансовой) отчетностиㄹ․

Например, в случае дачи взятки сотруднику организации-покупателя для получения возможности выиграть тендер (конкурс) организация-поставщик подкупает преимущество по сравнению со своими конкурентами. В этом случае у нее появляется возможность увеличивать цены, за счет чего будут компенсированы расходы на дачу взятки организации-покупателя. В данной ситуации у организации-покупателя искажения данных бухгалтерской (финансовой) отчетности не возникает, так как упущенная экономическая выгода не отражается в бухгалтерском учете и финансовой отчетности. Однако у организации-поставщика для оплаты «услуг» взяткополучателю возникает необходимость изъятия части средств в любой форме из своего оборота. Поскольку каждый факт хозяйственной жизни в соответствии с Ф3-402 предполагает наличие подтверждающих оправдательных документов, «маскирующих» фактическую суть расхода, то осуществление такого факта «заставляет» руководство организации-поставщика сформировать пакет фальсифицированных документов, обосновывающих списание требуемой суммы денежных средств. У организации-поставщика возникает искажение данных финансовой (бухгалтерской) отчетности.

Факты незаконного присвоения активов и коррупции имеют косвенное влияние на достоверность показателей бухгалтерской (финансовой) отчетности, так как бухгалтеры, составляющие ее, могут быть не осведомлены о фактах осуществленных мошеннических действий. Например, такие ситуации возможны в силу объемности и множественности фактов хозяйственной жизни осуществляемых денежных платежей, необнаруженного факта хищения актива после проведения инвентаризации либо в тот период, когда ее проведение не планировалось.

2 Уголовный кодекс Российской Федерации от 13.06.1996 N 63-ФЗ (ред. от 29.07.2017) (с изм. и доп., вступ. в силу с 26.08.2017), п. 1, ст. 204. 
Анализ результатов и содержания заключений экспертов в области экономики показывает, что чем выше занимаемая должность работника в экономическом субъекте, совершившего мошенническое действие, тем масштабнее риск и величина материальных последствий.

\section{Предпосылки применения форензик-контроля организациями}

Предпосылками применения форензик как методического инструментария является совершение или возможность совершения мошеннических действий в организациях, имеющих отраслевые особенности.

В настоящее время для отдельных отраслей характерна значительная пространственная разобщенность производственного процесса, что существенно усложняет возможность контроля соблюдения технологии производства, сохранности активов и целевого их использования. В качестве примера можно привести отрасли АПК, в которых бизнес-процессы осуществляются с момента производства полевых работ вплоть до сбора урожая, т. е. практически невозможно оценить, соблюдалась ли технологическая дисциплина в части внесения норм различных удобрений, норм высева, расходования горюче-смазочных материалов и т. п.

В сельскохозяйственных организациях, грузоперевозочных компаниях одной из отличительных особенностей является наличие мобильных внеоборотных активов, что повышает требования к контролю использования горюче-смазочных материалов, запасных частей. Высокая ликвидность оборотных средств и готовой продукции также является существенным фактором возможности осуществления мошеннических действий. В условиях расположения производственных объектов на территории или вблизи сельских поселений с развитым личным подворьем многократно повышаются риски хищений как оборотных средств (семян, удобрений, кормов и т. д.), так и готовой продукции (молока, зерна, картофеля и т. д.).

В связи с этим для собственников организаций возможны следующие риски злоупотреблений:

- на уровне высшего менеджмента - незаконное присвоение активов и искажение данных бухгалтерского учета и отчетности, организация параллельных производств, сговора с поставщиками по ценам и т. п.;

- на уровне среднего и низшего звена в основном незаконное присвоение активов.

Результаты обзора источников информации показывают, что многие авторы характеризуют форензик как использование навыков аудита и финансового расследования для документального исследования подсистемы экономической информации, результаты которого в форме заключения используются в качестве доказательств в судебном процессе. Однако форензик не ограничивается только этими видами работ. Его применение позволит выявить:

- значительные отклонения в стоимости понесённых текущих и капитальных затрат;

- некорректность информации, представляемой собственнику, кредитору или работодателю;

- некорректно составленный бизнес-план;

- сокрытие получаемых доходов;

- механизм вывода активов и проведения его юридической оценки;

- перечень организаций и физических лиц, участвующих в отмывании денежных средств;

- завышение стоимости объектов недвижимости и др.

Результаты проводимых исследований показывают, что существует большое количество видов работ, которые могут быть выполнены в рамках форензик-контроля, перечень выполняемых работ расширяется в зависимости от ситуации и потребности заказчика. Следует отметить, что существует и другой подход к раскрытию сущности и содержания форензик, а следовательно и его применения. Так, отдельные авторы считают форензик результатом труда специалистов по судебной бухгалтерии (forensic accounting) и компьютерной экспертизе (computer forensics). При этом задачами специалистов по судебной бухгалтерии являются оценка размера материальных последствий, определение механизма сокрытия фактов мошенничества в бухгалтерском учете и отчетности и способы их выявления. Экспертизы в области IT осуществляют специалисты по информационным технологиям, которые изучают носители информации с целью обнаружения «цифровых доказательств».

В зависимости от целей, задач, предмета проведения форензик алгоритм, процедуры, информационная база будут иметь отличия, среди которых можно выделить следующие:

- выявление возможной противоправной деятельности ответственных лиц, связанных с той или иной формой хищения;

- проверка контрагентов перед заключением договоров поставки, предоставления услуг или сделок M\&A в рамках процедур оценки бизнеса (Due diligence);

- оценка рисков несостоятельности, банкротства или реорганизации экономического субъекта. 
Методические аспекты форензик-контроля как инструмента...

Основой проведения форензик-контроля является информационная база и процедуры ее исследования. Эксперты в области форензик изучают подсистемы бухгалтерского учета, информационной, финансовой и экономической безопасности, внутреннего контроля; правильность оформления фактов хозяйственной жизни и подтверждающих бухгалтерских записей; наличие или отсутствие денежных средств, материальных ценностей и других видов активов; обоснованность оприходования или списания материальных ценностей и денежных средств; причины возникновения недостач и излишков; качество проведенной инвентаризации/ревизии; объем причиненного материального ущерба в результате кражи или мошенничества сотрудников экономического субъекта. Особое внимание уделяется проверке добросовестности контрагентов и сотрудников организации на предмет наличия конфликта интересов. Выявление нестандартных ситуаций позволяет использовать математические методы и информационные технологии для проведения качественного форензик с привлечением IT-специалистов.

Анализ результатов проведенного исследования показывает, что привлечение независимых специалистов по расследованию финансовых преступлений в России менее популярно, чем в мировой практике. Однако наиболее надежным методом выявления мошеннических действий является независимое экономическое расследование - форензик, или внесудебная экономическая экспертиза.

Поскольку в настоящее время форензик проводится в интересах собственников, акционеров, совета директоров, наблюдательного совета, инвесторов, крупных кредиторов и других лиц, заинтересованных в деятельности экономических субъектов, то при разработке программы форензик необходимо исходить из его целевой направленности, задач, методов и технологии осуществляемых процедур в рамках защиты интересов собственников бизнеса.

Рассматривая содержание форензик как инструмента выявления нестандартных ситуаций в деятельности экономических субъектов, необходимо исходить из того, что он объединяет в себе аудит любых направлений, юридический и налоговый консалтинг, документальную ревизию, комплаенс-контроль, риск-менеджмент и др. По нашему мнению, форензик более всего сравним с финансовым аудитом. Однако если при аудите идет проверка соответствия бухгалтерской (финансовой) отчетности установленным нормам, то проведение форензик в большей степени нацелено на выявление мошеннических действий, условий их осуществления и отражения в подсистеме экономической информации.

Как инструмент выявления неправомерных фактов хозяйственной жизни и действий сотрудников в деятельности организации, форензик способствует решению первоочередных задач, соотнесенных с отраслевой спецификой исследуемого субъекта:

- оценка эффективности организации внутренних бизнес-процессов по производству и отгрузке продукции покупателям;

- обеспечение проведения внутреннего финансового расследования;

- разработка эффективной системы финансовой и экономической безопасности субъектов;

- выявление фиктивных контрагентов поставки;

- обеспечение эффективного и прозрачного взаимодействия с контрагентами и др.

В исследовании Ж. А. Кеворковой [15] показано, что анализ результатов проведенных исследований, систематизация и обобщение выявленных мошеннических действий, возможных злоупотреблений и нарушений позволяют выявить нестандартные ситуации, при наличии которых необходимо проведение форензик-контроля:

- при осуществлении мониторинга наблюдается постоянный рост расходов при сохранении на прежнем уровне показателя выручки;

- при уменьшении величины выручки наблюдается рост дебиторской и кредиторской задолженности;

- осуществляется недостоверный учет активов и обязательств, доходов и расходов;

- выявляется оплата заключенных фиктивных договоров;

- существует непрозрачная процедура выбора поставщиков при организации тендеров (конкурса);

- установлены случаи невозврата выданных кредитов и займов;

- наблюдается отсутствие аналитического учета;

- осуществляется в полном объеме предоплата при закупках товаров, работ, услуг;

- имеют место необоснованные максимальные отсрочки и рассрочки платежей при отгрузке и продажах продукции;

- установлена сомнительная (параллельная) практика ведения бизнеса;

- выявляются контрагенты-посредники и неблагонадежные контрагенты; 
- выявляются группы контрагентов, связанных между собой;

- осуществляется оптимизация налоговых баз и др.

Применение того или иного контрольного инструмента осуществляется в определенной последовательности, что характерно и для форензик. В рамках проведения форензик изначально устанавливается перечень видов деятельности, транзакций, бизнес-процессов, отдельных фактов хозяйственной жизни, которые необходимо детально исследовать. В отличие от экономической экспертизы специалисты форензик могут применять любые методы вплоть до методов фактического контроля.

Поскольку при проведении форензик эксперт может применить любые методы, не противоречащие законодательству и не приводящие к порче объектов исследования, то, на наш взгляд, выявление мошеннических действий и нестандартных ситуаций, возможных злоупотреблений и нарушений можно осуществить с применением следующих методов и процедур:

- интервью с представителями экономического субъекта с целью детального понимания бизнес-процессов производства и продажи продукции;

- комплексная документальная ревизия деятельности экономического субъекта в интересах заказчика форензик с целью выявления необоснованного списания оборотных и внеоборотных активов, обязательств, резервов, чистой прибыли и пр.;

- выявление фактов мошеннических действий, осуществленных сотрудниками и наемным персоналом экономического субъекта, например, организация неучтенного производственного объекта;

- проверка корректности и полноты отражения существенных фактов хозяйственной жизни в бухгалтерском учете и бухгалтерской (финансовой) отчетности, особенно в части учета готовой продукции, ее отгрузки и определения финансового результата;

- анализ используемых экономическим субъектом «мошеннических схем» по выводу или хищению активов;

- выявление нестандартных фактов хозяйственной жизни, отраженных в бухгалтерском учете, и искаженной информации в бухгалтерской (финансовой) отчетности;

- анализ системы закупок товаров, достоверности и реальности установленных цен и добросовестности контрагентов;
- сбор и анализ информации по контрагентам, в том числе по связанным сторонам, сомнительным и недобросовестным, контрагентам, объявленным банкротами;

- анализ потенциальных финансовых, кредитных, налоговых и других видов рисков;

- анализ структуры доходов и расходов экономического субъекта;

- анализ данных бухгалтерского и налогового учета и др.

\section{Заключение}

В экономической литературе методические аспекты форензик-контроля исследуются в течение длительного времени. Причины и факторы мошенничества высших должностных лиц с использованием служебного положения исследовались Эдвином Х. Сазерлендом в 30-е гг. XX в. В последующем исследования проводились российскими и зарубежными учеными, раскрывающими теоретические и исторические положения развития форензика. В статье разработаны современные методические подходы к форензику как методу контроля, выявлены его преимущества и недостатки, возможности использования при проведении проверок и установлении фактов мошенничества. Исследование проводилось на основе использования общенаучных и специальных методов познания. В настоящее время среди ученых дискуссионным является вопрос в части выявления порядка и последовательности возникновения мошенничества, которое в дальнейшем может быть определено как экономическое преступление. На основе проводимых исследований в статье отмечается, что количество видов работ, необходимых при проведении форензик-контроля, является значительным и в большей степени зависит от потребностей заказчика. Особое внимание уделяется применению контрольных инструментов, в частности выявлению противоправных действий ответственных лиц, проверке контрагентов перед заключением договоров поставки, сделок в рамках процедур оценки бизнеса, оценки рисков. При осуществлении форензик-контроля могут быть применены и другие методы, исходя из сущности и содержания выявленной нестандартной ситуации. В настоящее время не существует общих, универсальных методик выявления мошеннических действий, но применение форензик-контроля уменьшает риск их возникновения. Отдельным направлением исследования являются проблемы подготовки кадров. 


\section{Конфликт интересов}

Автор декларирует отсутствие явных и потенциальных конфликтов интересов, связанных с публикацией настоящей статьи.

\section{Библиографический список}

1. Cressey D. R. Why Do Trusted Persons Commit Fraud? A Social-Psychological Study of Defalcators // Journal of Accountancy. 1951. Vol. 92. P. 576-577.

2. Crumbley D., Heitger L., Smith S. Forensic and Investigative Accounting. Chicago, IL : CCH, 2015.

3. Dreyer K. A History of Forensic Accounting. Grand Valley State University, 2014.

4. Hermanson D. R. The Fraud Diamond: Considering the Four Elements of Fraud // The CPA Journal. 2004. Vol. 74 (12). P. 38-42.

5. Hernandez R. D., Groot T. Fraud in corporations: Control of prevention that reduce the risk of fraud. Working paper. Free University of Amsterdam. 2007.

6. Kranacher M. J., Riley R., Wells J. T. Forensic accounting and fraud examination. John Wiley \& Sons, 2011.

7. Manning G. Financial Investigation and Forensic Accounting. Boca Raton : Taylor \& Francis Group. 2005.

8. Ozili P. Forensic accounting and fraud. A review of literature and policy implications // International journal of accounting and economic disciplines. 2015. No. 3 (1). P. 63-68.

9. Ozkul F. Y., Pamukcu A. Detection of fraud and forensic in the field of accounting // Fraud in the emerging economies. 2012. No. 1. P. 19-41.
10. Rezaee Z. Causes, consequences, and deterence of financial statement fraud. Critical Perspectives on Accounting. 2005. No. 16 (3). P. 277-298.

11. Sutherland E. H. Principles of Criminology. Chicago : University of Chicago Press, 1924.

12. Sutherland E. H. White Collar Crime. New York : Holt, Rinehart \& Winston, 1949.

13. Городилов М. А., Шкляева Н. А. Форензик в рамках экспертно-аналитической и аудиторской деятельности : теоретическое исследование понятия // Учет. Анализ. Аудит. 2018. Т. 5, № 2. C. $72-79$.

14. Исаева Е., Лебедев И. Управление рисками корпоративного мошенничества // Финансовый директор. 2010. № 3. URL: https://clck.ru/SUqbY (дата обращения: 20.10.2020).

15. Кеворкова Ж. А. Форензик: реальность и действительность для российских экономических субъектов // Экономика. Бизнес. Банки. 2018. № 1. C. $166-173$.

16. Когденко В. Г. Корпоративное мошенничество : анализ схем присвоения активов и способов манипулирования отчетностью // Экономический анализ: теория и практика. 2015. № 4 (403). С. 2-13.

17. Суйц В. П., Анушевский И. И. Форензик : методы и методика финансового расследования // Аудит и финансовый анализ. 2014. № 6. С. 216-226.

18. Уэллс Дж. Т. Справочник по предупреждению и выявлению корпоративного мошенничества. М. : Маросейка, 2008.

19. Харланд Э., Хабирова Р. Мошенничество: легче предотвратить, чем выявить. М. : Harvard Business Review, 2011.

Кеворкова Жанна Аракеловна, доктор экономических наук, профессор, профессор департамент аудита и корпоративной отчетности ФГОБУ ВО «Финансовый университет при Правительстве Российской Федерации», Москва, Российская Федерация

E-mail: zhanna.kevorkova@mail.ru

ORCID ID: 0000-0002-8674-4216

Поступила 30.09.2020

Подписана в печать 26.10.2020 


\title{
Methodological aspects of forensic control as a tool for detecting and preventing fraudulent actions in the activities of economic entities
}

\author{
Zh. A. Kevorkova ${ }^{1}$ \\ ${ }^{1}$ Financial University under the Government of the Russian Federation, 49, \\ 125993, Leningradsky Ave., GSP-3, Moscow, Russian Federation
}

Cite as: Kevorkova, Z. A. (2020) Methodological aspects of forensic control as a tool for detecting and preventing fraudulent actions in the activities of economic entities. Proceedings of Voronezh State University. Series: Economics and Management. 4, 43-53. (In Russ., abstract in Eng.) DOI: 10.17308/econ.2020.4/3192

\begin{abstract}
Subject. The article reveals the methodological aspects of forensic analysis as a tool for detecting and preventing fraudulent actions in the activities of economic entities. The goal orientation and effectiveness of the use of Forensis as a method used in inspections are justified. At the same time, it is shown that the use of forensic analysis as a tool for detecting fraudulent actions in economic entities has certain features associated with the industry specifics of the subject under study.

Goals/objectives. The study of the range of services provided by organizations working in this field has been expanded. It is proved that when solving issues on this issue, there are a large number of controversial provisions that require scientific research, which is disclosed in this article, and the key factors that are necessary to identify falsified financial statements are identified.

Methodology. The research was carried out using both General scientific methods of cognition, including analysis, classification, systematization, generalization, comparison, and private methods. It is determined that the application of the method of forensic control as a tool for detecting fraudulent actions in economic entities is associated with certain difficulties. when applying it, it is necessary to take into account both economic and legal provisions.

Results. The analysis of the economic entity's activity and its information base is aimed at identifying fraud indicators that indicate the possible presence of fraudulent actions in relation to the economic entity under study.

Conclusions. The study of methodological developments and the results obtained from the use of forensic allowed us to identify problems, the solution of which is aimed at developing proposals for its use as a tool for detecting and preventing fraudulent actions in the activities of economic entities.
\end{abstract}

Key words: forensic analysis; fraudulent actions; forensic tasks; forensic method, financial investigations, out-of-court economic expertise.

Conflict of Interest

The author declare the absence of obvious and potential conflicts of interest related to the publication of this article.

\section{References}

1. Cressey, D. R. (1951) Why Do Trusted Persons Commit Fraud? A Social-Psychological Study of Defalcators. Journal of Accountancy. 92, 576-577.

2. Crumbley, D., Heitger, L. \& Smith, S. (2015) Forensic and Investigative Accounting. - Chicago, IL : $\mathrm{CCH}$.

3. Dreyer, K. (2014) A History of Forensic Accounting. Grand Valley State University.

4. Hermanson, D. R. (2004) The Fraud Diamond: Considering the Four Elements of Fraud. The CPA Journal. 74 (12), 38-42.
5. Hernandez, R. D. \& Groot, T. (2007) Fraud in corporations: Control of prevention that reduce the risk of fraud. Working paper. Free University of Amsterdam.

6. Kranacher, M. J., Riley, R., \& Wells, J. T. (2011) Forensic accounting and fraud examination. John Wiley \& Sons.

7. Manning, G. (2005) Financial Investigation and Forensic Accounting. Boca Raton: Taylor \& Francis Group.

8. Ozili, P. (2015) Forensic accounting and fraud. A review of literature and policy implications. International journal of accounting and economic disciplines. $3(1), 63-68$. 
9. Ozkul, F. Y. \& Pamukcu, A. (2012) Detection of fraud and forensic in the field of accounting. Fraud in the emerging economies. 1, 19-41.

10. Rezaee, Z. (2005) Causes, consequences, and deterence of financial statement fraud. Critical Perspectives on Accounting. 16(3), 277-298.

11. Sutherland, E. H. (1924) Principles of Criminology. Chicago: University of Chicago Press.

12. Sutherland, E. H. (1949) White Collar Crime. New York: Holt, Rinehart \& Winston.

13. Gorodilov, M. A. \& Shklyaeva N. A. (2018) Forensic within the framework of expert-analytical and auditing activities: theoretical research of the concept. [Accounting. Analysis. Audit]. 5 (2), 72-79. (In Russ.)

14. Isaeva, E. \& Lebedev, I. (2010) Corporate Fraud Risk Management. Financial Director. 3. URL: https:// clck.ru/SUqbY (accessed: 20.10.2020 г.)
15. Kevorkova, Z. A. (2018) Forensic: reality for Russian economic subjects. Economy. Business. Banks. 1, 166-173. (In Russ.).

16. Kogdenko, V. G. (2015) Corporate fraud: asset misappropriation schemes analysisand ways to manipulate reporting. Economic analysis: theory and practice. 4 (403), 2-13. (In Russ.).

17. Suyts, V.P., Anushevsky I.I. (2014) Forensic: financial investigation's methods and methodology. [Audit and financial analysis]. 6, 216-226. (In Russ.)

18. Wells, J. T. (2008) Corporate Fraud Handbook. Prevention and Detection. Hoboken, N.J. : John Wiley \& Sons Limited.

19. Harland, E. \& Khabirova, R. (2011) Fraud: easier to prevent than to identify. Moscow, Harvard Business Review. (In Russ.)

Kevorkova Zhanna Arakelovna, Dr. Sci. (Econ.), Prof., professor of the Departament of audit and corporate reporting of Financial University under the Government of the Russian Federation, Moscow, Russian Federation

E-mail: zhanna.kevorkova@mail.ru

ORCID ID: 0000-0002-8674-4216

Received 30.09.2020

Accepted 26.10.2020 